Western University Scholarship@Western

Centre for the Study of International Economic Centre for the Study of International Economic

Relations Working Papers

Relations

1983

\title{
Tenure Security and Urban Squatting
}

Emmanuel Jimenez

Follow this and additional works at: https://ir.lib.uwo.ca/economicscsier_wp

Part of the Economics Commons

Citation of this paper:

Jimenez, Emmanuel. "Tenure Security and Urban Squatting." Centre for the Study of International Economic Relations Working Papers, 8305C. London, ON: Department of Economics, University of Western Ontario (1983). 
ISSN $0228-4235$

ISBN $0-7714-0418-2$

CENTRE FOR THE STUDY OF INTERNATIONAL ECONOMIC RELATIONS

WORKING PAPER NO. $8305 \mathrm{C}$ DSU

TENURE SECURITY AND URBAN SQUATTING

Department of Economics Library

Emmanuel Jimenez

$A P R=9.9983$

University of Western Ontario

This paper contains preliminary findings from research work still in progress and should not be quoted without prior approval of the author.

Department of Economics

UNIVERSITY OF WESTERN ONTARIO

LONDON, CANADA

N6A 5 C2 

Partial support for this paper was provided by the World Bank under its Research Project No. 672-46, headed by S. Mayo. Professor $R$. A. Hackenberg, University of Colorado and Director of the Davao Action Information Centre, provided the data base. The author acknowledges the expert research assistance of Serena $\mathrm{Ng}$ and helpful comments received from J. R. Follain, C. Lim, S. Mayo, G. MacDonald, W. Wheaton and participants of workshops at MIT and at the Universities of Toronto and Western Ontario, but accepts full responsibility for any remaining errors. The ideas expressed herein are the author's own and do not reflect the official views of the World Bank or any other institution.

Department of Economics Library

$$
\text { APR } \supset 91983
$$

University of Western Ontario 


\begin{abstract}
While recent studies have shown that up to $35 \%$ of the total urban population of the Third World live in squatter settlements, there is a dearth of economic analysis on the phenomenon of squatting. This paper attempts to fill this gap theoretically, by modifying existing models of tenure choice to account for risk and empirically, by using a unique data set for a developing country. The equilibrium model argues that the difference in unit housing prices between the non-squatting (forma1) sector of a city and its squatting (informal) sector reflects the premium associated with a secure tenure status. The conditions, under which households of different types, such as income groups, allocate themselves among squatting communities associated with various risks of eviction are then derived. The empirical portion of this paper uses hedonic price techniques to derive the average premium on tenure security in a mediumsized Philippine city, Davao. Results show that formal-sector unit dwelling prices are about $18 \%$ (renters) to $58 \%$ (owners) more than in the informa1 sector. These equilibrium price differentials were found to be greater for lower income groups, larger household sizes and households with older heads for renters and younger heads for owners. These groups would thus tend to be in areas associated with greater eviction probabilities.
\end{abstract}




\section{Introduction}

It has been estimated that $30-35 \%$ of the total urban population of the Third World (and up to $40-50 \%$ in some of its largest cities) Iive in squatter settlements, where households do not own or rent the land on which they live but are illegally dwelling on it (Mountjoy, 1976; Grimes, 1976; Ulack, 1978). Many communities appear overnight on land which may have been vacant for a number of reasons. The land may have been government owned and reserved for some future use; recreational; or marginal, such as rightsof-way for transport networks, marshes, floodplains, ravines or hillsides. The land may have been privately owned and kept vacant for speculative purposes, which is an option that is particularly attractive in developing countries where relatively disorganized financial markets constrain other opportunities for investment.

One of the goals of the recent innovative attempts, led by international aid agencies such as the World Bank, to upgrade urban shelter standards in low income areas has been the rationalization of land tenure schemes (see Wor Id Bank, 1980). The se efforts have been handicapped by a lack of information regarding the parameters which determine squatting behavior. For example, in a squatter upgrading project which included, as one of its components, the provision of secure tenure, information regarding how much different types of recipient households would be willing to pay for that security would be essential in evaluating the magnitude of the distributional implications of this type of project or in calculating user charges. This paper is an attempt to begin to fill this substantial gap in the theoretical and empirical literature by introducing the use of economic analysis to the 
study of the issues in squatting, which have heretofore been addressed primarily by noneconomists in the social sciences (see Peattie and Aldrete-Haas, 1981, for a recent review of the prodigious literature compiled by antropologists, planners, political scientists, sociologists and geographers). The most difficult task in evaluating security of tenure is its measurement. If a time series were available, the solution would be relatively straightforward. The objective probability of being evicted would be the proportions of squatters evicted over, say, any given year. If present or prospective squatters guess correctly and equate their subjective probability with the objective probability, then the latter, which is measurable, can be used in economic models of behavior. In practice, such a time series is unavailable in developing countries. An extensive search failed to yield any yearly counts of squatters and evictions. However, the literature documents evidence that there is considerable variation in the perception of eviction over a city. Doebele (1983), for example, cites studies in which different levels of housing investment in a city are attributed to perceived differences in tenure security. If households are correct and there is also an objective variation in tenure security, then cross-section data can be used to characterize that variation. Another question that needs to be answered, of course, is why there might be objective differences in tenure security within a city. While a complete theoretical exposition is beyond the scope of this paper, some of the reasons include: differences in the opportunity cost of the land which is the subject of the squatting; differences in the cost to the government of evicting squatters from particular settlements, due perhaps to varying degrees of community organization (see Jimenez for a further discussion of this point); or differences in the tenure status of certain plots of land, as ownership may be disputed. 
These and other reasons lead to a distribution of probabilities of eviction for various areas in the city.

This paper attempts to obtain a measure of the value of security of tenure among squatter households in Davao, a medium-sized city in the southern Philippines, by taking advantage of the dispersion in probabilities discussed above. A choice-theoretic conceptual framework is used to argue that, in equilibrium, the difference in unit housing prices between otherwise identical units in the non-squatting (formal) sector and the squatting (informal) sector reflects the premium associated with a secure tenure status. A large observed difference might be the result of a relatively high level of perceived risk of eviction. Moreover, if there is a discrepancy in this premium among households who face similar risk levels but are otherwise different in terms of socioeconomic characteristics, the various premia can be expected to measure differences in attitudes toward risk.

The conceptual framework for the analysis is an adaptation of the model described in Jimenez (1982b), and is outlined in Section II. Squatting is considered to be an alternative mode of tenure with uncertain prices in the future, depending on the household's expectations regarding the probability of being evicted. Certain houses and locations are associated with different probabilities and households of different types bid for these locations. The equilibrium value of tenure security associated with a particular location is the unit price differential between formal and informal sector housing which equilibrates utility in the two sectors and which represents the highest "bid"in the informal sector. The empirical measure of this differential is described in Section III and is based on data from a medium-sized city, Davao, 
in the Philippines. Section IV is an attempt to infer how squatter households of various socioeconomic characteristics will sort themselves out among squatter locations which are associated with different risk levels.

\section{Conceptual Framework}

Consider a city of a fixed size in which there is an amount of land (which is also fixed in size) that is available for squatting. These assumptions are made in order to simplify the model. Squatting land is available due to the institutional reasons described earlier. This implies a short-run framework in which housing, which is assumed to be a composite commodity that yields a continuous flow of services, is characterized by an upward sloping supply curve. ${ }^{2}$ Moreover, in the squatting sector, this supply is situated on land associated with various levels of security of tenure. This is consistent with what has been documented for developing countries, where some communities are "10w risk" types which are quite old (Ulack). Some of the reasons for this have already been discussed in the previous section. The probabilities of eviction associated with different sites are exogenous to the model.

Each household is presumed to behave as one individual agent and accepts . housing prices which are market-determined in each sector, as given. This section then examines what are the parameters which a prospective squatter about to enter the city faces in a simple one period world. Household equilibrium is characterized, first, when there is only one type of household and secondly, when there are many types.

Household Equilibrium: One Type of Household

In this subsection, all households are assumed to be alike. Each household maximizes utility with respect to a flow of housing services, $h$, and a composite commodity, $x$, under the parameters faced in the formal sector 
market and under squatting. The household chooses the mode of tenure which yields the greater utility.

If the representative household were to choose not to squat, it would maximize utility $u(x, h)$ subject to the constraint that $W=p h+x$, where $W \equiv$ wealth and $p \equiv$ the price per unit of formal housing services. The price p can be interpreted as an implicit rental price of housing or as some unit ownership cost. If $\mathrm{p}$ is to be interpreted as the latter, it would include financing costs, depreciation, maintenance, foregone interest income, differences in the income tax treatment of renters and owners, net of expected capital gain, per unit of housing services. It is assumed that $x$ is the numeraire. The usual first-order condition would be:

$$
\frac{u_{h}}{u_{x}}=p .
$$

Solving for the optimal values of $x$ and $h$ would yield the indirect utility function:

$$
\mathrm{V}=\mathrm{u}[\mathrm{W}-\mathrm{ph} *(\mathrm{~W}, \mathrm{p}), \mathrm{h} *(\mathrm{w}, \mathrm{p})] \equiv \mathrm{v}(\mathrm{W}, \mathrm{p})
$$

The household who squats and who is "successful"--i.e., is not evicted--obtains a price of housing $\mathrm{p}_{s}$ and faces a budget constraint $W=x_{n}+p_{s} h_{n}$. The subscript $n$ signifies the consumption of the composite commodity and housing services under the "not evicted" state of nature. However, if a squatter household were evicted, it would have to incur moving costs and, possibly, a penalty. These are assumed to be a lump-sum cost $\mathrm{C}^{3}$ Moreover, in this model, the squatter household must precommit itself and spend money on housing services ex ante, that is, before the household finds 
out whether it is evicted or not. Thus, the evicted squatter would Iose whatever it has invested in the settlement and, in addition, would have to find alternative accommodation. It is assumed that it must buy housing in the formal sector at a given price $p$ if it is evicted. The budget constraint in this state of the world would thus be $W=x_{e}+p_{e}+C+p_{s} h_{n}$, where e signifies the "evicted" state of nature. 4

Squatters thus face two possible budget constraints, depending upon whether or not they are evicted. The perceived probability of eviction, $\pi$, is assumed to be accepted as given to the squatting household. Faced with two possible budget constraints and the probabilities that one would apply rather than the other, the squatter household is assumed to choose its ex post consumption bundle by maximizing: $E u=\pi u\left(x_{e}, h_{e}\right)+(1-\pi) u\left(x_{n}, h_{n}\right)$. Substituting in the budget constraint would yield:

$$
U^{S}=\pi u\left(W-C-p h_{e}-p_{s} h_{n}, h_{e}\right)+(1-\pi) u\left(W-p_{s} h_{n}, h_{n}\right)
$$

where $\mathrm{U}^{\mathrm{S}} \equiv \mathrm{Eu}^{\mathrm{s}}$, the expected utility of the household. Maximizing would yield optimal bundles of $h_{e}^{*}$ and $h_{n}^{*}$ as functions of the parameters. With interior solutions, the first-order conditions would be:

$$
\begin{aligned}
& -p u_{x_{e}}+u_{h_{e}}=0 \\
& -p_{s}\left\{[\pi /(1-\pi)]_{x_{e}}+u_{x_{n}}\right\}+u_{h_{n}}=0 .
\end{aligned}
$$

These conditions would yield demand equations for optimal amounts of housing services under both states of nature: $h_{e}^{*}=h_{e}^{*}\left(W, C, p, p_{s}, \pi\right)$ and $h_{n}^{*}=h_{n}^{*}\left(W, C, p, p_{s}, \pi\right)$. Substituting $h_{e}^{*}$ and $h_{n}^{*}$ into (3) would yield the following indirect expected utility function: 


$$
\begin{aligned}
& v^{s}=\pi v^{e}+(1-\pi) v^{n}, \quad \text { where } \\
& v^{e} \equiv v^{e}\left(w, c, p, p_{s}, \pi\right)=u\left[w-c-p{ }_{e}^{*}\left(w, c, p, p_{s}, \pi\right)\right. \\
& \text { - } \left.p_{s} h_{n}^{*}\left(W, c, p, p_{s}, \pi\right), h_{e}^{*}\left(W, C, p, p_{s}, \pi\right)\right] \text {, } \\
& v^{n} \equiv v^{n}\left(W, C, p, p_{s}, \pi\right)=u\left[W-p_{s} h_{n}^{*}\left(W, C, p, p_{s}, \pi\right), h_{n}^{*}\left(W, C, p, p_{s}, \pi\right)\right] .
\end{aligned}
$$

The $v(\cdot)$ 's are thus the indirect utility function under both states of nature and $v^{e}<v^{n}$. The amount, per unit of housing services, that a representative household is willing to pay to achieve a given level of expected utility, $v^{s}$, can be derived by solving (5) for $p_{s}$ :

$$
p_{s}=p_{s}\left(\pi, W, C, p, V^{s}\right)
$$

W, $C$ and the distribution of $\pi^{\prime}$ s are determined outside the model. For the moment assume there is only one level of $\pi$ in the city. The equilibrium levels of $\mathrm{p}_{\mathrm{s}}$ and $\mathrm{p}$ are the prices which would clear the markets in the two residential sectors. The representative household compares its utility under the illegal sector with that under the formal sector to decide whether to squat or not. Analytically, this implies that a household will squat if $V<V^{S}$. If the level of utility available in the formal sector were less than that in the informal sector, households would become squatters and raise housing prices until the difference in $\mathrm{p}$ and $\mathrm{p}_{S}$ was sufficient to compensate for taking the risk as a squatter. This would be a level of $\mathrm{p}_{s}$ which equated utility in the two sectors. For all households to be in equilibrium, then, prices must be such that $\mathrm{V}$ equal $\mathrm{V}^{\mathrm{S}}$. Thus, there would be no incentive for a household to prefer squatting over living in the legal sector. The equilibrium condition is therefore:

$$
v(W, p)=v_{0}=v_{0}^{s}=\pi v^{e}\left(W, c, p, p_{s}, \pi\right)+(1-\pi) v^{n}\left(W, c, p, p_{s}, \pi\right),
$$


where the "o" subscript denotes equilibrium levels of utility. The equilibrium gap between $p_{s}$ and $p$ is the amount, per unit of housing service, which would be sufficient to induce a household to be indifferent between living in the formal sector and being a squatter with a given chance, $\pi$, of being evicted. 5

Thus far the analysis has assumed only a unique value of $\pi$. However, as described in the introduction, there is usually a given range of $\pi_{k}$ for various squatter settlements, where $k=0, \ldots, 1$. A settlement that was reasonably wellestablished would have a $\pi$ that would be close to zero. Thus, in equilibrium $\mathrm{P}_{\mathrm{s}}$ should be close to $\mathrm{p}$. For settlements with higher levels of $\pi$, if households are risk averse, households would be willing to settle only for relatively lower values of $p_{s}$. Since $\pi_{k}$ is fixed for each location, observed unit housing prices, $p_{s}$, are equivalent to what a household would be willing to bid for that particular level of risk.

The locus of combinations of $p_{s}$ and $\pi$ which would make a household indifferent between squatting and not squatting is depicted in Figure 1 , under the assumption that $v^{e}$ and $v^{n}$ are monotone and continuous in $\pi$ and $p_{s}$. The farther away is the locus from the origin, the worse off will the household be. This locus is downward sloping. It is shown in the appendix that, holding $\mathrm{V}^{\mathrm{S}}$ fixed at the equilibrium level, $\mathrm{V}_{\mathrm{o}}^{\mathrm{s}}$ :

$$
\left(\frac{\partial \pi}{\partial p_{s}} \mid v_{o}^{s}\right)=h_{n}^{*}\left[\pi v_{w}^{e}+(1-\pi) v_{w}^{n}\right] /\left(v^{e}-v^{n}\right)<0
$$

Intuitively, this is so because, from any given point on a 1ocus, an increase in the cost of being a squatter, $\mathrm{p}_{s}$, would result in a loss of utility, which would have to be compensated by a drop in $\pi$. The "height" of $V^{S}$ in equilibrium would depend on the level of $V$, utility in the formal sector, and, ultimately, the population, income and other exogenously determined characteristics which 
determine the demand and supply for housing in the city. The convexity of the locus is assumed since, as is shown in the Appendix, it depends upon behavioral parameters. The exact shape is not important to the analysis. If there is no segmentation in the formal sector so that there is a unique level of $p$, Figure 1 shows that the difference between $p$ and $p_{s}$ will increase as $\pi$ increases. This difference can be interpreted as the amount that a household's bid for squatter housing will differ from the formal sector price at given levels of $\pi$. Given risk aversion, $p>p_{s}$, so that $v^{s}$ is everywhere to the left of the dotted line.

Household Equilibrium: More Than One Type of Household

The previous subsection examined the case in which households are homogeneous in terms of income and other characteristics. However, if there were more than one type of household, (2), (5) and (6) would have to be indexed to denote an equilibrium relationship only for a particular household type. Let $\alpha$ represent a set of characteristics which affect behavior (taste, household composition, etc.). For the $j^{\text {th }}$ type squatter household, for example, its utility level in the " $k$ th" type of settlement is:

$$
v_{j}^{s}=\pi_{k} v^{e}\left(w_{j}, c_{j}, p, p_{s k}, \pi_{k}, \alpha_{j}\right)+\left(1-\pi_{k}\right) v^{n}\left(w_{j}, c_{j}, p, p_{s k}, \pi_{k}, \alpha_{j}\right)
$$

where $\pi$ denotes the probability of being evicted associated with a particular settlement, and $\mathrm{p}_{s k}$ is the household's willingness to pay for a unit of housing services at that settlement. 
The derivation of an equilibrium vector of informal sector housing prices follows the arguments developed in the literature on bid rents in housing markets (see Henderson, 1977, Ch. 6; Rosen, 1974; and Wheaton, 1977). Otherwise homogeneous housing units which are associated with different probabilities of being evicted are rented or sold to the highest bidder. In equilibrium the number of units over which each household type has the highest bid must equal the number of households in that group. The number of households, in turn, depends upon the level of utility in the formal sector for that household type. Let subscript " $k_{j}$ " be the index of that location household $\mathrm{j}$ occupies at an equilibrium. At equilibrium:

$$
v_{o j}=v_{o j}^{s}=\pi_{k_{j}} v^{e}\left(w_{j}, c c_{j}, p, p_{s k_{j}}, \pi_{k_{j}}, \alpha_{j}\right)+\left(1-\pi_{k_{j}}\right) v^{n}\left(w_{j}, c c_{j}, p, p_{s k_{j}}, \pi_{k_{j}}, \alpha_{j}\right)
$$

for the $j^{\text {th }}$ type of household. To obtain equilibrium across all household types, indifference curves must be compared for each group of consumers to determine the highest bidder for a particular location.

At equilibrium, the outer envelope of consumer bids exactly represents the price profile obtained when consumers maximize utility. To show this, consider two types of individuals, types $i$ and $j$, whose equilibrium utility levels are depicted in Figure 2, so that $v_{o j}^{s}=v_{o j}$ and $v_{o i}^{s}=v_{o i}$. Let $\pi_{k}$ and $\pi_{k_{j}}$ denote $j$ 's and $i^{\prime}$ s respective equilibrium locations associated with a particular probability of eviction. By the definition of equilibrium

$$
\mathrm{p}_{s k_{j}}^{j}>\mathrm{p}_{s k_{i}}^{j},
$$

that is, j's bid for its equilibrium location is greater than i's bid. If $\mathrm{P}_{s k_{j}}^{j}$ is $\mathrm{j}^{\prime} s$ bid in its equilibrium location, its utility there must be equivalent at point $A$ in Figure 2 as point $B$, where individual $j$ would bid $p_{s k_{j}}^{i}$ for $I^{\prime} s$ equilibrium location, or 


$$
v_{o f}^{s} \equiv v_{j}^{s}\left[\pi_{k_{j}}, p_{s k_{j}}^{j}, w_{j}, c_{j}, p, \alpha_{j}\right]=v_{j}^{s}\left[\pi_{k_{i}}, p_{s k_{j}}^{i}, w_{j}, c_{j}, p, \alpha_{j}\right] \text {. }
$$

Since $j$ 's bid for $i$ 's location is less than $i$ 's winning bid, which is $p_{s k_{i}}$, it must be that:

$$
v_{o j}^{s}=v_{j}^{s}\left[\pi_{k_{i}}, p_{s k_{j}}^{i}, w_{j}, c_{j}, p, \alpha_{j}\right]>v_{j}^{s}\left[\pi_{k_{i}}, p_{s k_{i}}^{i}, w_{j}, c_{j}, p, \alpha_{j}\right]=v_{1 j}^{s} .
$$

This shows that $j$ 's utility in its winning zone is greater than the utility obtainable in i's winning zone at the price that $i$ would bid. Thus, the equilibrium set of bid rents would be the outer envelope of the utility-maximizing households' indifference curves in probability-price space. The concavity or convexity of the equilibrium price locus will depend upon the assumptions regarding the shape of the utility locus for each household type.

An interesting issue is which type of households will locate at "safer" locations. Suppose that all households were similar except for wealth. Once again, for this example, the problem is limited to two types of households, rich and poor. If it were determined that rich households are like the type "i" households discussed above, then, they would outbid the poorer households for the settlements which have lower probabilities of eviction. Let $\tilde{\pi}$ denote (in Fig. 2) the probability where $v_{o j}^{s}$ and $v_{o i}^{s}$ cross. Given the result explained in the previous paragraph, then, higher income households would outbid lower income households for locations with more security of tenure (1ower $\pi$ ) if, at $\tilde{\pi}$,

$$
\left(\frac{\partial \pi}{\partial p_{s}} \mid \text { Rich }\right)>\left(\frac{\partial \pi}{\partial p_{s}} \mid \text { Poor }\right)
$$

Since $\frac{\partial \pi}{\partial p_{s}}<0$, this would, of course, mean that the absolute value of the slope of the rich-group utility locus would be less than that of the poor group. Conversely, if the reverse condition held, the poor would locate where the probability of eviction was lower. Thus it is not unambiguously true that poor households will locate in the riskiest settlements. 
To determine the conditions under which this holds, the change in $\left(\partial \pi / \partial p_{s}\right)$ with respect to a change in $W$ is determined at $\tilde{\pi}$, ceteris paribus. The resulting expression, which is derived in the Appendix, is:

$$
\partial\left[\partial \pi / \partial p_{s} \mid v_{0}^{s}\right] / \partial w=\left(\partial \pi / \partial p_{s} \mid v_{o}^{s}\right)(\epsilon-\rho-\delta) / w
$$

where $\epsilon \equiv\left(\partial h_{n} / \partial W\right)\left(h_{n} / W\right)$, is the income elasticity of housing demand as a squatter; $\rho \equiv-W_{W W}^{n} / v_{W}$, the Arrow-Pratt relative risk aversion measure; and $\delta \equiv W\left(v_{W}^{e}-v_{W}^{n}\right) /\left(v^{e}-v^{n}\right)$, the income elasticity of the spread in utility between the "evicted" and "not evicted" states of nature.

Suppose that $\varepsilon, \rho$ and $\delta$ were invariant with respect to income. The slope (7) denotes the amount of price decline which would induce a squatter household to accept another unit of uncertainty while holding its level of well-being fixed. According to (9), since $\rho$ approaches unity ${ }^{6}$ and assuming $\delta<0$ (due to risk aversion, $v_{W}^{e}>v_{W}^{n}$ ), a sufficient condition for this price decline to be less for richer than poorer households is that $\epsilon>1$. This implies, of course, that the slope (7) of the probability-price locus decreases (becomes more steep) as income rises, given $\pi$. Thus a sufficient condition for richer households to outbid poorer households for riskier locations is that housing demand be income elastic. However, recent empirical studies have shown that the demand for housing is relatively income inelastic (see Mayo, 1981, for evidence on developed countries; Follain et al, and Jimenez and Keare, forthcoming, for evidence on developing countries). Thus, the sign of (9) is ambiguous. What can be said is the following: the greater is the measure of relative risk aversion in relation to the income elasticity of housing demand, the more likely it is that rich people will outbid poorer people for locations which are "safer". 
The intuition underlying the result described above follows from the proposition that if housing demand were relatively income inelastic, the amount of decline in housing prices which would be needed to compensate for a greater risk will be greater for high income households than low income households. This is because the benefit from the lower housing prices is dependent upon housing consumption. If the difference in housing consumption between the rich and poor were less than proportional to the difference in income, the poor would benefit more if $\mathrm{p}_{\mathrm{s}}$ were to decline by the same amount for a slight increase in $\pi$. To keep utility constant, $p_{s}$ must fall more for richer households.

It can also be shown that the greater are costs, C, the less steep would the $\left(\pi, p_{s}\right)$ locus be and thus, the more likely are households to be located in safer areas. The analytics of this intuitive result can be found in Jimenez (1982b).

\section{Empirical Formulation and the Data}

The theoretical results outlined in the preceding section indicate that a greater observed differential in equilibrium unit housing prices between the formal sector and a squatting community implies that households associate a greater probability of eviction with that squatting community. This can be seen in Figure 3, where type 2 households outbid type 1 households for safer locations. The heavy line is the equilibrium set of bid prices for the city. The goal of this section of the paper is to measure this average price differential, and thus, the average probability of eviction for the informal sector of a medium sized city in the Philippines. We will also examine how this differential varies by household characteristics to determine the types of households which locate in safer parts of the city. 
The primary difficulty lies in a reliable measure of unit housing prices, $p$ and $p_{s}$, which are unobservable, since $h$ and $h_{s}$ are composite commodities which are made up of a vector of characteristics, $z$. A rough but useful measure would be to use the hedonic price technique to hold constant for housing characteristics in comparing actual (or, in the case of owners, implicit) rental values in the formal and informal sectors.

Let $R$ and $R_{S}$ denote observed rents in the formal and informal sectors, respectively:

$$
\begin{aligned}
& R=p h(z)=R(z, p) \\
& R_{S}=P_{s} h_{s}\left(z_{s}\right)=R_{s}\left(z_{s}, P_{s}\right) .
\end{aligned}
$$

These equations assume that unit housing prices are independent of the level of characteristics consumed. ${ }^{7}$ We now further assume that for any given mix of characteristics, $\tilde{z}, h(\tilde{z})=h_{s}(\tilde{z})$ or the consumption technology is such that a similar bundle of characteristics in either sector implies the same service flow of the composite commodity. Under these assumptions we can calculate:

$$
R\left(z_{s}, p\right) / R_{s}\left(z_{s}, p_{s}\right)=p / p_{s} .
$$

That is, the ratio of what a squatter's home would rent out for in the formal sector relative to its actual rental value would be equal to the relative difference in unit housing prices. The equilibrium price ratio $\mathrm{p} / \mathrm{p}_{\mathrm{s}}$ is, in general, expected to be greater than unity because of the uncertainty in the squatting sector and risk averse behavior.

The step that remains to be explained then, is how $R\left(z_{s}, p\right)$ is to be generated. The hedonic equation that relates $\mathrm{R}$ to the characteristics in the formal sector is first estimated, to yield $\hat{R}(z, p)$. Then the vector of characteristics of the squatter sector, $z_{s}$, is inserted into this estimated equation describing the structure of formal sector rents, to derive $\hat{R}\left(z_{s}, p\right)$. This is 
then used to calculate $(12)$, where $R\left(z_{s}, p_{s}\right)$ is the actual squatter rent. 8

The appropriate functional form for the hedonic equation cannot, in general, be specified a priori on theoretical grounds. Recently, urban economists have imbedded their choice of functional form in a Box-Cox framework (see, for example, Quigley, 1982; Halvorsen and Pollakowski, 1981; Linneman, 1981 ; Goodman, 1978). In this paper, we thus use the following transformation:

$$
R^{(\lambda)} \equiv \beta_{0}+\sum_{i=1}^{m} \beta_{i} z_{i}+\epsilon
$$

where $R \equiv d$ dwelling unit rent (or sale value, for the case of owners); $z_{i}$ is the consumption of the $i^{\text {th }}$ characteristic; $\beta_{i}$ 's are parameters to be estimated; $\epsilon$ is the random error term; $m$ is the number of characteristics; and $R^{(\lambda)}=\left(R^{\lambda}-1\right) / \lambda$. To simplify the estimation procedure it is assumed that the independent variables are not to be transformed and that a flexible functional form is unwarranted (see Halvorsen and Pollakowski), as is done in most of the other hedonic studies. The random sample used in the analysis is of 3,344 households in Davao, a medium-sized city in the southern Philippines. Of these households, 1,505 were squatters (489 were renters and 1,016 were owners of the structure). The rest were non-squatters and included 887 renters and 952 owners. The interviews were conducted in 1979 by the Davao Action Information Center, a private research foundation, which kindly provided cleaned tapes for this analysis.

Separate equations for renters and owners were estimated because the data base does not have similar measures of monthly rent, to be used as the dependent variable in (13), for these two groups. For renters, actual monthly rent is used. The equivalent variable for owners is the estimated sale value, as appraised by the occupiers. A recent study for another group of squatters in 
the Philippines (see Jimenez, 1982a) indicated that the latter measure tends, on average, to be similar to that obtained from a professional appraiser. Among renters and owners, squatters are separated from non-squatters. Covariance tests indicate that this segmentation was warranted.

The mean housing and household characteristics which are used in this analysis are reproduced in Table 1 for each of the subsamples. There are roughly five groups of housing characteristics: size (number of rooms), quality (structural, wall and floor quality indices), basic urban services (garbage collection; phone, water and electrical connections), neighborhood characteristics (average income in the neighborhood, the dispersion of average income, the presence of a covered drain in front of the dwelling unit) and location (distance to the CBD).

The figures in Figure 1 indicate that, within each of the formal and squatting sectors, owners, who are on average richer than renters, tend to have larger dwellings, although there are no discernible differences in quality and access to services. Owners also tend to live further out from the CBD. More interesting comparisons can be made between the squatter and nonsquatter groups. Non-squatters have larger dwellings than squatters but the former's advantage in terms of dwelling unit quality is not significant. While squatters appear to have difficulty in obtaining access to services such as garbage collection and telephone connection, they are able to obtain essential services, such as waste disposal, water and electrical connection as well as their formal sector counterparts. As expected, squatters live in poorer neighborhoods and have a significantly lower proportion of houses with covered drains. The income in their neighborhoods also appears to be, on average, significantly more concentrated than in the formal sector. Finally, when one examines household characteristics, while there are significant differences in average income, the differences (20\% for renters and $34 \%$ for owners) are not as large as one might 
expect. Indeed the income profile (not shown) indicates that about $15 \%$ of squatters belong in the top $20 \%$ of the overall Davao income distribution. These figures tend to confirm the "new view" among social scientists (see Peattie and Aldrete-Haas) that squatters are not disparate marginal households who have no other choice but to forego the formal sector.

\section{Empirical Results}

The first step in the empirical analysis is the estimation of the hedonic relationship (13) for renters and owners of the formal sector. The results for linear, semi-log, and Box-Cox specifications are presented in Tables 2 and 3 . It should be noted that the statistical package used to estimate the Box-Cox equation via maximum likelihood methods may produce underestimates of the standard errors (see Spitzer and Blackley, et al). However, the extent of this bias has yet to be determined in the literature. Thus, few statements about significance are made below. For renters, the functional form which maximizes Box-Cox likelihood function is one in which $\lambda$ approaches zero, which makes this equivalent to the semi-log.

The results for the hedonic equation indicate that most of the coefficients are of the proper sign. The variables which measure quantity (number of rooms) and quality (structural condition, wall material quality and floor material quality) are all positively related to rent or sale value. The coefficients for basic urban services display less consistent behavior. For renters, the coefficients of the other urban services such as the provision of water services, sanitary facilities, garbage collection, electrical and phone connections, and drainage have the expected signs. For owners, three of these are of the wrong sign, although they also have low levels of significance, even with standard errors which are underestimated. 
As expected, distance from the city center and the average income of the neighborhood are negatively and positively related, respectively, to the dependent variable. An interesting finding is that an increase in the heterogeneity of the neighborhood in terms of income leads to a decline in housing value.

In the second stage of the empirical analysis, the results summarized in Tables 2 and 3 are used to predict the rental or sale value of squatter housing. Since these coefficients reflect the role of formal sector housing characteristics in formal sector value, this procedure predicts the rent that squatter housing, with a particular set of characteristics, would obtain, had that housing been in the formal sector:

$$
\hat{R}\left(z_{s}, p\right)=\left[\left(1+\hat{\lambda} \hat{\beta}_{o}\right)+\hat{\lambda} \sum_{j=1}^{13} \hat{\beta}_{j} z_{s j}\right]^{1 / \hat{\lambda}}
$$

This calculation of $\hat{R}\left(z_{s}, p\right)$ can be compared with $R_{s}\left(z_{s}, p_{s}\right)$, the rent that is actually paid for a house with a set of $z_{s}$ characteristics. Since we are dealing with a similar level of housing services, the ratio must reflect differences in unit prices to compensate for risk. In relative terms :

$$
\hat{R}\left(z_{s}, P\right) / R_{s}\left(z_{s}, P_{s}\right)=p / p_{s}
$$

These ratios, averaged for each of the squatter subsamples, are 1.177 for renters and 1.578 for owners.

The results indicate that, on average, a squatter dwelling would rent out for approximately $18 \%$ more if it were in the formal sector. For squatter owners, the mean difference is considerably greater--the sale value for the same dwelling unit would increase by over half. This result is to be expected given the costs of eviction for these two tenure groups, although the two 
ratios are difficult to compare because of different measures of rent. The strict comparison of renter and owner behavior will be the subject of future work. The relative difference for each subgroup can be interpreted as the market valuation of the security of tenure. According to the theory outlined in the previous section, if households are in equilibrium, the reciprocal of this ratio is the discount in formal sector housing prices which is necessary to induce an average household to accept a particular level of risk of being evicted in the squatting sector. This discount would be expected to be larger, the greater is the perceived risk.

Since there is a given distribution of risks associated with different plots in the community, differences in household characteristics and risk preference would imply different discounts for various socioeconomic groups. These differences in household characteristics would have certain implications for the costs of being evicted, relative risk aversion, and so on. In equilibrium, those with the smallest discount for a particular level of risk would obtain the plot associated with that risk. In order to gain some insight into which types of households bid for and obtain riskier areas, the ratio, $\hat{R}\left(z_{s}, p\right) / R_{s}$, is regressed on socioeconomic characteristics such as income, household size and the age of head. Once again, in this analysis, we assume that households perceive the same level risk associated with a dwelling unit. The regression results for the semi-log and double-log forms are reported on Tables 4 and 5. The results for other functional forms (quadratic and linear) are quite similar and are not reproduced here. The means of the independent variables are at the bottom of Table 1 . Permanent income is obtained from a predicted value of an equation that regressed current income on a number of relevant variables. 9 
The most consistent result is that income is negatively related to relative prices. The coefficients for current and permanent income measures are less than zero and significantly so for all the specifications. The interpretation of this result can be seen by first recalling that, in equilibrium, there is a downward sloping relationship between $\pi$ and $P_{s}$. If there is no segmentation in the formal housing market, this implies that at higher levels of eviction probabilities, we should observe greater differences in the ratio of unit prices in the formal sector relative to unit prices in the informal sector. This equilibrium relationship was shown to be the envelope of "highest bids" by various socioeconomic groups. The empirical result indicates that higher income groups face lesser differentials in relative unit housing prices. Thus, they must tend to locate in sites which are relatively safe. Conversely, poorer households tend to locate in places which have relatively high probabilities of eviction associated with them. This result is in accord with our expectations, as discussed in the theoretical section, given prevailing estimates for the income elasticity of housing demand and priors about the Arrow-Pratt measure of relative risk aversion.

The results for the demographic variables indicate that larger household sizes will be associated with a larger difference in housing prices although the coefficients for most of the specifications are not particularly significant. This would imply that households with larger families will tend to locate in areas which are relatively less "safe", which, at first glance, seems surprising since the larger families probably have to incur greater costs if evicted. However, it should be noted that household income is being held constant and larger families would imply lower income per person. 
For renters, age of head is positively (although weakly) associated with relative differences in housing prices, which indicates that older renter households will tend to locate in squatter neighborhoods with higher eviction probabilities. For owners, the trend is exactly the opposite and owner occupying households with older heads tend to outbid younger ones for safer locations. One explanation for this is that, among owners, older households will have greater eviction costs due to loss of status and the fact that they have had a greater opportunity to consolidate their dwelling and, indeed, even their property rights to a location. For renters, such considerations are unimportant and renter families with older heads are likely to be those with little to lose and who would prefer the chancier locations at a lower price.

Because of the relatively low explanatory power of the equations in Tables 4 and 5 , the empirical results of the second part of this analysis should be appropriately caveated. Household' characteristics other than the ones included in this study may be important in determining which households bid for what type of site. However, the low $R^{2}$ 's are not surprising given the cross-section nature of the data base and the findings for the characteristics which are included yield interesting insights.

\section{Summary, Conclusions, and Implications}

Recent studies have shown that up to $35 \%$ of the total urban population of the Third World live in squatter settlements. Efforts to rationalize land tenure schemes in cities where illegal dwellings proliferate have been hampered by a lack of information regarding the parameters which determine squatting 
behavior, such as the value of tenure security. This paper is an attempt to begin to fill this gap theoretically, by modifying existing models of tenure choice to account for risk and empirically, by using a unique data set for a developing country.

The conceptual framework assumes a city with a fixed population and a distribution of potential squatting sites with different risks. The paper argues that, in equilibrium, the difference in unit housing prices--between the non-squatting (formal) sector of a city and its squatting (informal) sector reflects the premium associated with a secure tenure status. The basic model examines the case of one type of household which regards squatting as an alternative mode of tenure with uncertain prices in the future, depending upon its expectations regarding the probability of being evicted. The extended model considers many types of households who sort themselves out among the various squatting communities in the city depending upon their characteristics. It is shown that, if there are two types of households, one rich and the other poor, the richer households will outbid poorer ones for safer squatter neighborhoods depending upon the size of the income elasticity of housing demand relative to the Arrow-Pratt measure of relative risk aversion. The empirical portion of the paper uses hedonic price techniques to derive the average premium on tenure security in a medium-sized Philippine city, Davao. The results show that formal-sector unit dwelling prices are about $18 \%$ (renters) to $58 \%$ (owners) more than equivalents in the informal sector. These equilibrium price differentials were found to be greater for lower income groups, larger household sizes and households with older heads for renters and younger heads for owners. These groups would thus tend to be 
in areas associated with greater eviction probabilities. While these figures are derived through a technique based on some simplifying assumptions for a city in a particular enviroment and thus should not be accepted as widely applicable for every city with a squatter community, they are indicative that premia for tenure security do exist.

One important application of the results of this research is in the design and pricing of urban development projects which grant tenure security to their beneficiaries. For the city of Davao, this paper has been able to obtain average estimates of the market valuation of tenure security. Moreover, the benefits of secure tenure will differ depending upon the perceived risk of eviction, which is capitalized into the price of dwellings. If the structure of risks were not taken into account into its design, a project which uniformly provided tenure to all types of squatter communities would have significant distributional implications. For example, if our conclusions for the Davao sample are correct, low income households would benefit more than their high income counterparts from such a project.

The findings also offer one explanation why it would not be unusual to find relatively low-priced squatter dwellings in vacant areas among properties which are quite attractive and which may be settled by the city's elite. Since the risks of eviction are likely to be greater in these areas, the findings of this study would indicate that poorer squatter households would "outbid" richer ones for such locations. 


\section{APPENDIX}

Squatter households are assumed to maximize the following expected utility function:

$$
U^{S}=\pi u\left[W-c-p h_{e}-p_{s} h_{n}, h_{e}\right]+(1-\pi) u\left[W-p_{s} h_{n}, h_{n}\right]
$$

The first order conditions for this maximization problem are:

$$
\begin{aligned}
& -p u_{x_{e}}+u_{h_{e}}=0 \\
& -p_{s}\left\{[\pi /(1-\pi)] u_{x_{e}}+u_{x_{n}}\right\}+u_{h_{n}}=0
\end{aligned}
$$

which can be solved to yield demand equations for optimal amounts of housing services under both states of nature: $h_{e}{ }^{*}=h_{e}{ }^{*}\left(W, C, P, P_{s}, \pi\right)$ and $h_{n}{ }_{n}=h_{n}^{*}\left(W, C, p, P_{s}, \pi\right)$. The demand equations can be substituted into the expected utility function to yield the indirect expected utility function:

$$
v^{s}=\pi v^{e}+(1-\pi) v^{n}
$$

where $v^{e} \equiv v^{e}\left(W, C, p, p_{s}, \pi\right) \equiv u\left[W-C-p_{e}^{*}\left(W, C, p, p_{s}, \pi\right)-p_{s} h_{n}^{*}\left(W, C, p, p_{s}, \pi\right)\right.$, $\left.h_{e}^{*}\left(W, C, p, p_{s}, \pi\right)\right]$ and $v^{n} \equiv v^{n}\left(W, C, p, p_{s}, \pi\right) \equiv u\left[W-p_{s} h_{n}^{*}\left(W, C, p, p_{s}, \pi\right), h_{n}^{*}\left(W, C, p, p_{s}, \pi\right)\right]$. Note that $v^{e}<v^{n}$. We can write:

$$
\mathrm{P}_{\mathrm{s}}=\mathrm{p}_{\mathrm{s}}\left(\pi ; \mathrm{W}, \mathrm{C}, \mathrm{p}, \mathrm{v}^{\mathrm{s}}\right)
$$

Non-squatter households have an indirect utility function $v=v(W, p) \equiv$ $\mathrm{u}[\mathrm{W}-\mathrm{ph} *(\mathrm{~W}, \mathrm{p}), \mathrm{h} *(\mathrm{~W}, \mathrm{p})]$. In equilibrium, the following equation holds :

$$
v(W, p) \equiv v=v^{s} \equiv \pi v^{e}\left(W, C, p, P_{s}, \pi\right)+(1-\pi) v^{n}\left(W, C, p, p_{s}, \pi\right)
$$

Let us assume that preference orderings are continuous, monotonic, convex and homothetic. ${ }^{10}$ The slope $\left(\partial \pi / \partial p_{s}\right)$ for a given level of utility $\mathrm{V}_{\mathrm{o}}^{\mathrm{s}}$, in $\left(\pi, \mathrm{P}_{\mathrm{s}}\right)$ space, can then be determined by totally differentiating (A3): 


$$
\left(\partial \pi / \partial p_{s} \mid v_{0}^{s}\right)=-\left[\pi v_{p_{s}}^{e}+(1-\pi) v_{p_{s}}^{n}\right] /\left(v^{e}-v^{n}\right)
$$

which implies the locus is downward sloping. Using (A1) and deriving analogs to Roy's identity, i.e., $v_{p_{s}}^{e}=-h_{n}^{*} v_{W}^{e}(1+\eta) /(1-\alpha \varepsilon)$ and $v_{p_{s}}^{n}=-h_{n}^{*} v_{W}^{n}+$ $\left\{[\pi /(1-\pi)] h_{n}^{*} v_{W}^{e}(\alpha \epsilon+\eta) /(1-\alpha \epsilon)\right\}$, we can derive

$$
\left(\partial \pi / \partial p_{s} \mid v_{0}^{s}\right)=h_{n}^{*}\left[\pi v_{W}^{e}+(1-\pi) v_{W}^{n}\right] /\left(v^{e}-v^{n}\right)
$$

where $\eta \equiv\left(\partial h_{n}^{*} / \partial p_{s}\right)\left(p_{s} / h_{n}^{*}\right)$, the price elasticity of housing demand, $\alpha \equiv_{p_{s}} h_{n}^{*} / w$, a share equation, and $\varepsilon \equiv\left(\partial h_{n}^{*} / \partial W\right)\left(W / h_{n}^{*}\right)$, the income elasticity of housing demand.

In order to derive the conditions under which the locus is concave, differentiate (A5) with respect to $\mathrm{p}_{\mathrm{s}}$, holding everything else constant:

$$
\begin{array}{r}
\left(\partial^{2} \pi / \partial p_{s}^{2} \mid v_{o}^{s}\right)=\left\{\left[\left(v^{e}-v^{n}\right) \partial h_{n}^{*}\left[\pi v_{W}^{e}+(1-\pi) v_{W}^{n}\right] / \partial p_{s}\right]\right. \\
\left.-h_{n}^{*}\left[\pi v_{W}^{e}+(1-\pi) v_{W}^{n}\right] \partial\left(v^{e}-v^{n}\right) / \partial p_{s}\right\} /\left(v^{e}-v^{n}\right)^{2}
\end{array}
$$

To evaluate (A6), Roy's identity and Young 's theorem are used to derive $v_{W p_{s}}^{n}=v_{p_{s} W^{n}}^{n} ; v_{W p_{s}}^{e}=v_{p_{s}}^{e} ; \pi v_{p_{s}}^{e}+(1-\pi) v_{p_{s}}^{n}=-h_{n}^{*}\left[\pi v_{W}^{e}+(1-\pi) v_{W}^{n}\right]$. Thus, in the first term of (A6)'s bracketed expression:

$$
\begin{aligned}
\partial h_{n}^{*}\left[\pi v_{W}^{e}+(1-\pi) v_{W}^{n}\right] / \partial p_{s}= & -\left\{\left[\pi v_{W}^{e}+(1-\pi) v_{W}^{n}\right]\left(\partial h_{n}^{*} / \partial W\right)\right. \\
& \left.+\left[\pi v_{W W}^{e}+(1-\pi) v_{W W}^{n}\right] h_{n}^{*}\right\} \\
& +\left[\pi v_{W}^{e}+(1-\pi) v_{W}^{n}\right]\left(\partial h_{n}^{*} / \partial p_{s}\right) \\
& =h_{n}^{*}\left[\pi v_{W}^{e}+(1-\pi) v_{W}^{n}\right](\alpha \varepsilon-\eta) / p_{s} \\
& -h_{n}^{*}\left[\pi v_{W}^{e} r^{e}+(1-\pi) v_{W}^{n} r^{n}\right] / p_{s}
\end{aligned}
$$

where $r^{e} \equiv-r_{W W}^{e} / r_{W}^{e}, v^{n} \equiv-v_{W W}^{n} / v_{W}^{n}$, Arrow-Pratt absolute risk aversion measures. If we assume constant absolute risk aversion so that $r^{e}=r^{n}=r$, we can use $\rho=v W$, the Arrow-Pratt measure of relative risk aversion in (A7) and (A5) to derive: 


$$
\begin{aligned}
\left(\partial^{2} \pi / \partial p_{s}^{2} \mid v_{o}^{s}\right) & =-\left(\partial \pi / \partial p_{s} \mid v^{s}\right)\{\alpha(\varepsilon-\rho)-\eta \\
& \left.-p_{s}\left[\left(v_{p_{s}}^{e}-v_{p_{s}}^{n}\right) /\left(v^{e}-v^{n}\right)\right]\right\} / p_{s}
\end{aligned}
$$

In order to find out whether or not, at any given level of $\pi$, this utility locus becomes less or more steep as income changes, we simply have to differentiate (A5) with respect to $\mathrm{W}$ :

$$
\begin{aligned}
\partial\left(\partial \pi / \partial p_{s} \mid v_{0}^{s}\right) / \partial W & =\left\{\left[\pi v_{W}^{e}+(1-\pi) v_{W}^{n}\right]\left(\partial h_{n}^{*} / \partial W\right)\right. \\
& \left.+h_{n}^{*}\left[\pi v_{W W}^{e}+(1-\pi) v_{W W}^{n}\right]\right\} /\left(v^{e}-v^{n}\right) \\
& -h_{n}^{*}\left[\pi v_{W}^{e}+(1-\pi) v_{W}^{n}\right] /\left(v^{e}-v^{n}\right)
\end{aligned}
$$

Using (A5), the terms defined earlier, and letting $\delta \equiv W\left(v_{W}^{e}-v_{W}^{n}\right) /\left(v^{e}-v^{n}\right)$, the income elasticity of the spread in utility between the evicted and the unevicted states of nature, we can derive:

$$
\partial\left(\partial \pi / \partial p_{s} \mid v_{o}^{s}\right) / \partial W=\left(\partial \pi / \partial p_{s} \mid v_{o}^{s}\right)[(\epsilon-\rho)-\delta] / W
$$




\section{$\underline{\text { References }}$}

Arrow, K. (1971), Essays in the Theory of Risk Bearing, Markham. Blackley, P., Follain, J. R. and Ondrich, J. (1983), "Box-Cox Estimation of Hedonic Models: How Serious is the Iterative OLS Variance Bias?" Syracuse University, mimeo.

Doebele, W. (1983), "Selected Issues in Urban Land Tenure," in H. Dunkerley (ed.), Urban Land Policy, Oxford.

Follain, J., Lim, G. C., Renaud, B. (1981), "The Demand for Housing in Korea," Journa1 of Urban Economics.

Goodman, A. (1978), "Hedonic Prices, Price Indices and Housing Markets," Journal of Urban Economics, 5: $471-484$.

Grimes, 0. F. (1976), Housing for Low-Income Urban Families, Ba1timore: Johns Hopkins University Press.

Halvorsen, R. and Pollakowski, H. (1981), "Choice of Functional Form for Hedonic Price Equations," Journal of Urban Economics, 10: 37-49. Henderson, J. V. (1977), Economic Theory and the Cities, New York: Academic Press.

Jimenez, E. (1982a), "The Value of Squatter Dwellings in Developing Countries," Economic Development and Cultural Change, 30(4): 739-752.

Jimenez, E. (1982b), "Urban Squatting and Community Organization in Developing Countries: A Conceptual Framework," Centre for the Study of International Economic Relations, University of Western Ontario, Working Paper No. $8209 \mathrm{C}$ DSU. Jimenez, E. and Keare, D. H. (forthcoming), "Housing Consumption and Permanent Income in Developing Countries," Journal of Urban Economics.

Kihlstrom, R. and Mirman, L. (1981), "Constant, Increasing and Decreasing Risk Aversion with Many Commodities," Review of Economic Studies, 48 : 271-280. 
Linneman, P. (1981), "Some Empirical Results on the Nature of the Hedonic Price Function for the Urban Housing Market," Journal of Urban Economics, 8: $\quad 47-68$.

Mang1n, W. . (1967), "Latin American Squatter Settlements: A Problem and A Solution," Latin American Research Review, 2(2): 65-99.

Mayo, S. (1981), "Theory and Estimation in the Economics of Housing Demand," Journal of Urban Economics, $10(1): 95-116$.

Mountjoy, A. B. (1976), IUrbanization, the Squatter Development in the Third World," Tijdschrift voor Econ. en Soc. Geografie, 67 (3): 130-137.

Muth, R. (1969), Cities and Housing, Chicago: University Press. Quigley, J. (1982), "Nonlinear Budget Constraints and Consumer Demand: An Application to Public Programs for Residential Housing," Journal of Urban Economics, 12 : 177-201.

Peattie, S. and Aldrete-Haas, J. A. (1981), 'Marginal Settlements in Developing Countries: Research, Advocacy of Policy and Evolution of Programs," Ann. Rev. Sociol., 7: 157-75.

Rosen, S. (1974), "Hedonic Prices and Implicit Markets," Journal of Political Economy: $34-55$.

Spitzer, J. J. (1982), "A Primer on Box-Cox Estimation," Review of Economic Statistics, $64(2): 307-313$.

Stiglitz, J. (1969), "Behavior Towards Risk with Many Commodities," Econometrica, $37(4): 354-363$.

Ulack, R.: (1978), "The Role of Urban Squatter Settlements," Annals of the Association of American Geographers, $68(4):$ 535-550.

Wheaton, W. (1977), "A Bid Rent Approach to Housing Demand," Journal of Urban Economics, 4(2): 200-219.

World Bank (1980), Shelter, Washington, D.C. 


\section{Footnotes}

$I_{\text {These perceptions of security can, of course, be proxied by other }}$ variables. Vander Harst (quoted in Doebele, p. 124), for example, finds that the following variables may be important in Pakistan: tax collection, provision of electricity, plans for main gutter, paved roads, provision of community water tap, public street sweepers, age of settlement, condition of neighboring areas, whether the area has been mapped, and surveyed, the number of semistandard dwellings, community organizations, public latrines, public schools, medical facility, mail delivery and gas service. The theoretical reas on for including all of these variables is not clear in some cases. Also, relating these variables to another proxy for security of tenure--increased housing investment-- to test their validity in the relationship is also suspect. The use of these variables as proxies for tenure security is difficult in obtaining willingness to pay because the variables when consumed yield utility no matter what the tenure status might be.

2 The assumption that housing can be treated as a composite flow of services yielded by a structure, its characteristics, the land upon which it is built, the characteristics of the neighborhood where it is located, and the level of urban services to which it has access, is a standard method to circumvent the non-homogeneous and indivisible nature of housing as a commodity (see Muth). To explicitly account for the consumption of the specific housing characteristics (see Rosen) would complicate the analysis and detract from the main problem being considered in this paper. It is beyond the scope of the present version to explore the relationships between secure tenure and housing characteristics because data limitations prevent direct measures of tenure security. 
${ }^{3}$ It is possible, of course, that the costs of eviction may not be lump-sum but may be income-related. Nonpecuniary "psychic" costs may be higher for higher income households than low-income households. However, the most important component of the cost of being caught that is income related is the prospect of losing one's investment in the structure. If housing is a normal good, a higher income household which is an owneroccupier of the structure would lose more than a lower income household. This complication is already taken into account in the assumption that households must precommit housing expenditures (deposits for renters and the structure itself for owners). Because data limitations prevent the strict comparison of renter and owner housing expenditures, the paper does not consider the more general problem in which households also choose whether to rent or own.

${ }^{4}$ The one period framework and the precommitment allows us to determine ex ante prices. A model which allows households who are evicted to return and face $\mathrm{p}_{\mathrm{s}}$ once more can be incorporated in a more complicated multi-period described in footnote 5 below.

5 The assumption that all consumption must be committed prior to any eviction taking place allows us to determine prices without having to solve an intractable rational expectations problem concerning what prices are likely to be given who is evicted. Moreover, the analytical solution would become more complex in a multi-period framework in which ex post and ex ante prices must be reconciled since households would then have to make comparisons at each point in time. Simply comparing the present value of expected utility under the alternative states of nature would not be sufficient because we could not be certain that, for example, a household who chose to be a squatter in the first period and was subsequently evicted 
would always choose to be a squatter thereafter, due to the income effects of the penalty and lo.st precommitted housing expenditures.

6 In Arrow's (1971) words "broadly speaking, the relative risk aversion must hover around 1 , being if anything somewhat less for 1 ow wealths and somewhat higher for high wea1ths" (p. 98).

${ }^{7}$ An alternative approach would be to do the theoretical analysis in terms of demand for a vector of housing characteristics rather than a composite bundle. In this case, the willingness to pay would not be independent of consumption. This would greatly complicate the theoretical analysis (see footnote 2).

${ }^{8}$ Covariance tests are first carried out to ensure that the hedonic relationship differs for squatters and nonsquatters. It should also be noted that the alternative specification, to insert the nonsquatter characteristics into the squatter regression, was also attempted with substantially similar results.

${ }^{9}$ These variables include: household size, age of head, sex of head, regularity of nest consumption, furnishings, vehicle ownership, appliance ownership, years of education, whether or not the household is self-employed, whether the head has a white collar job and home ownership.

$10^{\circ}$ The conditions under which the Arrow-Pratt measure of risk aversion can be extended to a utility function which has more than one commodity are discussed in Stiglitz (1969) and Khilstrom and Mirman (1974, 1981). The problem arises because, unlike the one-commodity case, von Neumann-Morganstern utility functions of more than one dimension may represent different preference orderings on the 
set of commodity bundles. Thus, attempts to compare risk averseness of utility functions representing different ordinal preferences are confounded by differences in these preferences. Kihlstrom and Mirman (1981) obtain the result (Theorem 1) that if the preference orderings are continuous, monotonic, convex and homothetic and if a direct utility function $u$ is an increasing (decreasing, constant) relative or absolute representation of these preference orderings, then the indirect utility function $u$ inherits this property when considered as a function of income. This theorem is invoked to justify the use of the Arrow-Pratt measure with indirect utility. 
TABLE 1: Average Housing and Household Characteristics in the Two Sectors ${ }^{a}$

Housing Characteristics:

NROOMS Number of rooms in

STRUCCON Structural Condition

Index

WALLQ Wall Quality Index

FLOORQ Floor Quality Index

FLUSHWC Prop. of HH with

flush toilet

COLLGAR Prop. of HH with garbage collection

OWNPHONE Prop. of HH with phone access

WATER Water Facilities

Index

WIRE

MEANY

SDMEANY

DIST

COVDRN

covered drains

RENT Monthly Rent

SALE

Owner-assessed

$$
\mathrm{n}=489
$$

$R$

Squatters

$$
2.99
$$

(1.15)

2.79

(.61)

2.34

(.51)

2.23

(.51)

.56

(.50)

.21

(.41)

.02

(.15)

1.99

(.56)

.75

(.44)

1294.20

(545.6)

$$
1174.50
$$

(844.46)

3502.1

(2411.5)

.17

(.38)

97.99

(119.45)

sale value

Household Characteristics:

\begin{tabular}{llc} 
INCOME & $\begin{array}{l}\text { Monthly current } \\
\text { income }\end{array}$ & $\begin{array}{c}1133.60 \\
(1112.40)\end{array}$ \\
PERMINC & $\begin{array}{l}\text { Estimated permanent } \\
\text { incomeb }\end{array}$ & 964.76 \\
& HH Size & $561.69)$ \\
HHSIZE & & 5.33 \\
& Age of Head & $(2.07)$ \\
AGEH & & 36.69 \\
& & $(10.39)$ \\
\hline
\end{tabular}

$n=887$

Non-Squatters

$$
3.25
$$

(1.22)

2.84

(.62)

2.43

(.53)

2.22

(.45)

.66

(.47)

.67

(.47)

.10

(.30)

2.12

(.74)

.87

(.33)

1513.80

(609.85)

1617.10

(1316.30)

1665.3

(1432.8)

.27

(.45)

128.54

(139.15)

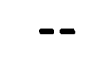

$$
\mathrm{n}=1016
$$

Owners

Squatters

3.65

(1.22)

2.78

(.58)

2. 31

(.55)

2.15

(.44)

.45

(.50)

.13

(.34)

.04

(.18)

1.92

(.42)

.70

(.46)

1182.30

(467.24)

1204.80

(1010. 70)

4436.6

(2755.3)

.11

(.31)

7938.5
$(12613.0)$

1357.40

(1537.60)

1117.80

(624.15)

5.43

(2.34)

38.10

(11.30)

$$
\begin{gathered}
1223.20 \\
(1362.20) \\
1047.00 \\
(569.26)
\end{gathered}
$$

6.45

(2.49)

43.29

(11.95)
11889.00

(17447.00)

Non-Squatters

4.01

(1.46)

2.89

(.62)

2.45

(.54)

2.24

(.52)

.58

(.49)

.50

(.50)

.12

(.32)

2.18

(.46)

.86

(.35)

1459.00

(625.52)

1517.90

(1256.80)

2481.5

(2138.7)

.28

(.45)

$$
\text { -- }
$$

1646.50

(2482.90)

1276.40

(694.99)

6.42

(2.65)

46.37

(12.83)

a Standard deviation in parentheses.

$b_{\text {This }}$ is a predicted value based on certain household characteristics. The equation is explained in the text. 
TABLE 2: Hedonic Equations (Renters)

\begin{tabular}{|c|c|c|c|}
\hline & Linear & Semi-Log & Box-Cox $(\hat{\lambda}=0)^{b}$ \\
\hline CONSTANT & $\begin{array}{r}-329.49 \\
(25.10)\end{array}$ & $\begin{array}{l}1.1975 \\
(.1418)\end{array}$ & \\
\hline NROOMS & $\begin{array}{l}20.178 \\
(3.544)\end{array}$ & $\begin{array}{l}.2113 \\
(.0020)\end{array}$ & \\
\hline STRUCCON & $\begin{array}{l}35.886 \\
(7.469)\end{array}$ & $(.0422)$ & \\
\hline WALLQ & $\begin{array}{l}23.955 \\
(8.343)\end{array}$ & $\begin{array}{l}.1382 \\
(.0471)\end{array}$ & \\
\hline FLOORQ & $\begin{array}{l}64.916 \\
(9.018)\end{array}$ & $\begin{array}{c}.3369 \\
(.0509)\end{array}$ & \\
\hline FLUSHWC & $\begin{array}{l}15.542 \\
(8.910)\end{array}$ & $\begin{array}{l}.3317 \\
(.0503)\end{array}$ & \\
\hline COLLGAR & $\begin{array}{c}8.977 \\
(8.072)\end{array}$ & .0 .1142 & \\
\hline WIRE & $\begin{array}{c}-6.956 \\
(11.100)\end{array}$ & $\begin{array}{l}.0962 \\
(.0627)\end{array}$ & \\
\hline OWNPHONE & $\begin{array}{c}63.873 \\
(12.526)\end{array}$ & $\begin{array}{l}.2156 \\
(.0708)\end{array}$ & \\
\hline WATER & $\begin{array}{c}6.678 \\
(4.758)\end{array}$ & $\begin{array}{l}.0167 \\
(.0269)\end{array}$ & \\
\hline COVDRN & $\begin{array}{l}38.084 \\
(8.407)\end{array}$ & $\begin{array}{l}.1318 \\
(.0475)\end{array}$ & \\
\hline DIST & $\begin{array}{l}-.0012 \\
(.0025)\end{array}$ & $\begin{array}{l}-.000025 \\
(.000014)\end{array}$ & \\
\hline MEANY & $\begin{array}{l}.0498 \\
(.0163)\end{array}$ & $\begin{array}{l}.000416 \\
(.000092)\end{array}$ & \\
\hline SDMEANY & $\begin{array}{l}-.0160 \\
(.0071)\end{array}$ & $\begin{array}{l}-.000155 \\
(.000040)\end{array}$ & \\
\hline $\mathrm{N}$ & 887 & 887 & \\
\hline$\overline{\mathrm{R}}^{2}$ & .49 & .62 & \\
\hline
\end{tabular}

a standard errors are in parentheses.

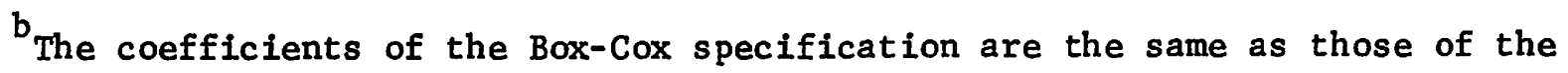
semi-log form. 
TABLE 3: Hedonic Equations (Owners)

\begin{tabular}{|c|c|c|c|}
\hline & Linear & Semi-Log & Box-Cox $(\hat{\lambda}=.06)$ \\
\hline CONSTANT & $\begin{array}{r}-45634 . \\
(2775.7)\end{array}$ & $\begin{array}{l}3.0654 \\
(.1986)\end{array}$ & $\begin{array}{l}2.0454 \\
(.3283)\end{array}$ \\
\hline NROOMS & $\begin{array}{l}1922.8 \\
(368.5)\end{array}$ & $\begin{array}{l}.2159 \\
(.0264)\end{array}$ & $\begin{array}{l}.3590 \\
(.0436)\end{array}$ \\
\hline STRUCCON & $\begin{array}{l}5726.4 \\
(890.4)\end{array}$ & $\begin{array}{l}.6783 \\
(.0637)\end{array}$ & $\begin{array}{l}1.1070 \\
(.1053)\end{array}$ \\
\hline WALLQ & $\begin{array}{l}1280.8 \\
(978.5)\end{array}$ & $\begin{array}{l}.4361 \\
(.0700)\end{array}$ & $\begin{array}{l}.7084 \\
(.1157)\end{array}$ \\
\hline FLOORQ & $\begin{array}{l}10922.0 \\
(1050.0)\end{array}$ & $\begin{array}{l}.3684 \\
(.0751)\end{array}$ & $\begin{array}{l}.6933 \\
(.1242)\end{array}$ \\
\hline FLUSHWC & $\begin{array}{c}1155.3 \\
(1016.6)\end{array}$ & $\begin{array}{l}.2245 \\
(.0727)\end{array}$ & $\begin{array}{l}.3744 \\
(.1202)\end{array}$ \\
\hline COLLGAR & $\begin{array}{l}-723.83 \\
(919.58)\end{array}$ & $\begin{array}{l}-.0297 \\
(.0658)\end{array}$ & $\begin{array}{l}-.0454 \\
(.1088)\end{array}$ \\
\hline WIRE & $\begin{array}{l}-1976.2 \\
(1289.6)\end{array}$ & $\begin{array}{l}.2960 \\
(.0923)\end{array}$ & $\begin{array}{l}.4243 \\
(.1525)\end{array}$ \\
\hline OWNPHONE & $\begin{array}{c}2526.2 \\
(1470.1)\end{array}$ & $\begin{array}{l}-.0616 \\
(.1052)\end{array}$ & $\begin{array}{l}-.0745 \\
(.1793)\end{array}$ \\
\hline WATER & $\begin{array}{c}356.66 \\
(436.35)\end{array}$ & $\begin{array}{l}.0073 \\
(.0312)\end{array}$ & $\begin{array}{l}.0165 \\
(.0516)\end{array}$ \\
\hline COVDRN & $\begin{array}{c}1437.5 \\
(1035.0)\end{array}$ & $\begin{array}{l}-.1114 \\
(.0740)\end{array}$ & $\begin{array}{l}-.1670 \\
(.1224)\end{array}$ \\
\hline DIST & $\begin{array}{l}.0264 \\
(.2173)\end{array}$ & $\begin{array}{l}-.000020 \\
(.000016)\end{array}$ & $\begin{array}{l}-.000028 \\
(.000026)\end{array}$ \\
\hline MEANY & $\begin{array}{c}3.6256 \\
(1.5244)\end{array}$ & $\begin{array}{l}.000322 \\
(.000109)\end{array}$ & $\begin{array}{l}.000577 \\
(.000180)\end{array}$ \\
\hline SDMEANY & $\begin{array}{l}.1621 \\
(.7075)\end{array}$ & $\begin{array}{l}-.000041 \\
(.000051)\end{array}$ & $\begin{array}{c}-.000075 \\
(.000084)\end{array}$ \\
\hline $\mathrm{N}$ & 952 & 952 & 952 \\
\hline$\overline{\mathrm{R}}^{2}$ & .50 & .60 & .61 \\
\hline
\end{tabular}


TABLE 4: Relative Unit Price Regressions (Renters)

Dependent Variables

\begin{tabular}{|c|c|c|c|c|}
\hline & & & & \\
\hline & $\underline{\text { LRATIO }}^{\mathrm{b}}$ & LRATIO & IRATIO & LRATIO \\
\hline CONSTANT & $\begin{array}{l}-.04941 \\
(.09181)\end{array}$ & $\begin{array}{l}-.04536 \\
(.09190)\end{array}$ & $\begin{array}{l}.56626 * * \\
(.28736)\end{array}$ & $\begin{array}{l}.8539 * * * \\
(.3457)\end{array}$ \\
\hline INCOME & $\begin{array}{l}-.000074 * * * \\
(.000021)\end{array}$ & & & \\
\hline PERMINC & & $\begin{array}{l}-.000156 * * * \\
(.000045)\end{array}$ & & \\
\hline AGEH & $\begin{array}{r}.00277^{\dagger} \\
(.00228)\end{array}$ & $\begin{array}{r}.003589 t \\
(.002310)\end{array}$ & & \\
\hline HHSIZE & $\begin{array}{l}.01039 \\
(.011736)\end{array}$ & $\begin{array}{l}.01645^{\dagger} \\
(.01229)\end{array}$ & & \\
\hline LINCOME & & & $\begin{array}{l}-.13473 * * * x \\
(.03656)\end{array}$ & \\
\hline LPERMINC & & & & $\begin{array}{l}-.19843 * * * \\
(.05344)\end{array}$ \\
\hline IAGEH & & & $\begin{array}{l}.08124^{\dagger} \\
(.05802)\end{array}$ & $\begin{array}{l}.10767 * \\
(.05897)\end{array}$ \\
\hline LHHSIZE & & & $\begin{array}{l}.05149 \\
(.05938)\end{array}$ & $\begin{array}{l}.07886^{\dagger} \\
(.06181)\end{array}$ \\
\hline$\overline{\mathrm{R}}^{2}$ & .021 & .020 & .023 & .024 \\
\hline $\mathbf{N}$ & 489 & 489 & 489 & 489 \\
\hline $\mathbf{F}$ & 4.44 & 4.37 & 4.95 & 5.02 \\
\hline
\end{tabular}

a"L" indicates the natural $\log$ of a number; Significance levels: $* * *=.01, * *=.05, *=.10, t=$ coefficient $>$ standard error.

$b_{\text {RATIO }}=\hat{R}\left(z_{s}, P\right) /\left(R\left(z_{s}, P_{s}\right)\right.$. 
TABLE 5: Relative Unit Price Regressions (Owners)

\begin{tabular}{|c|c|c|c|c|}
\hline & & Dependent & les & \\
\hline & LRATIO & LRATIO & LRATIO & LRATIO \\
\hline CONSTANT & $\begin{array}{l}.4680 * * * * \\
(.1163)\end{array}$ & $\begin{array}{l}4962 * * * \\
(.1147)\end{array}$ & $\begin{array}{l}1.5785 * * * \\
(.3537)\end{array}$ & $\begin{array}{l}2.6395 * * * \\
(.4042)\end{array}$ \\
\hline INCOME & $\begin{array}{l}-.000050 * * \\
(.000020)\end{array}$ & & & \\
\hline PERMINC & & $\begin{array}{l}-.000306 * x * \\
(.000051)\end{array}$ & & \\
\hline AGEH & $\begin{array}{l}-.006120 * * * t \\
(.002230)\end{array}$ & $\begin{array}{r}-.004051 * \\
(.002292)\end{array}$ & & \\
\hline HHSIZE & $\begin{array}{c}-.007768 \\
(.01781)\end{array}$ & $\begin{array}{l}.01414^{t} \\
(.01136)\end{array}$ & & \\
\hline LINCOME & & & $\begin{array}{l}-.1600 * * * x \\
(.0414)\end{array}$ & \\
\hline LPERMINC & & & & $\begin{array}{l}-.3806 * 2 x \\
(.0589)\end{array}$ \\
\hline LAGEH & & & $\begin{array}{c}-.1074^{\dagger} \\
(.0756)\end{array}$ & $\begin{array}{l}-.0408 \\
(.0757)\end{array}$ \\
\hline LHHSIZE & & & $\begin{array}{l}.0032 \\
(.0651)\end{array}$ & $\begin{array}{l}.1130 * \\
(.0677)\end{array}$ \\
\hline$\overline{\mathrm{R}}^{2}$ & .015 & .043 & .017 & .042 \\
\hline $\mathrm{N}$ & 1016 & 101.6 & 1016 & 1016 \\
\hline $\mathrm{F}$ & 6.00 & 16.07 & 6.98 & 15.96 \\
\hline
\end{tabular}




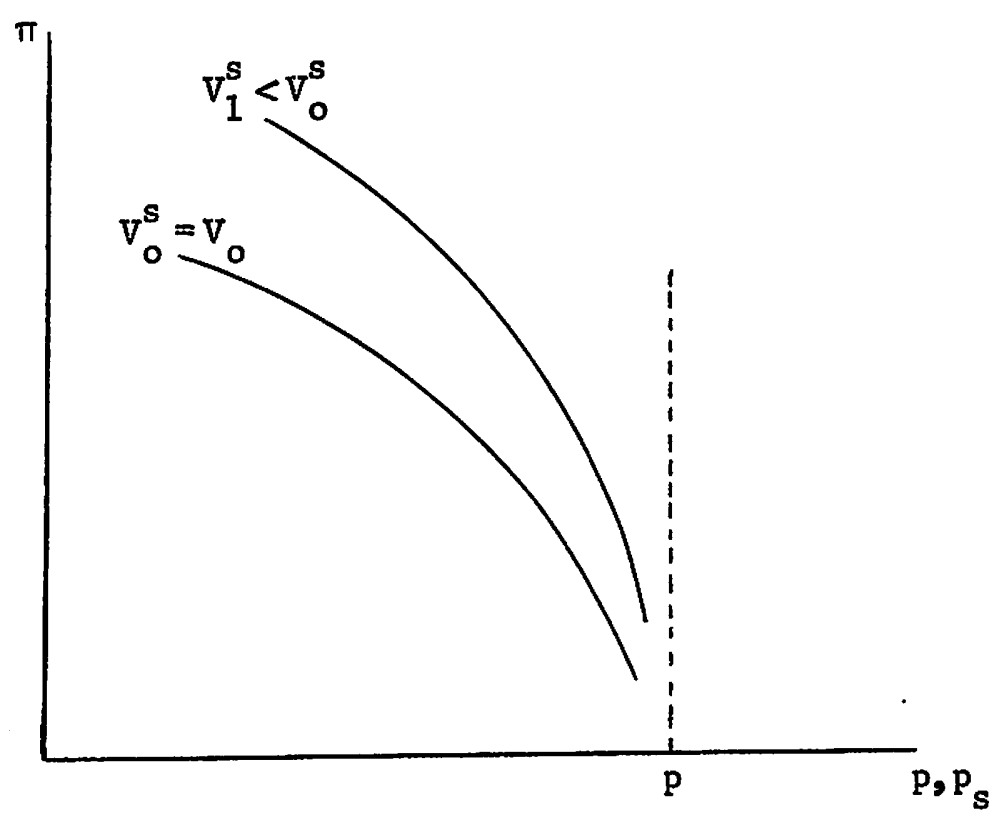

FIGURE 1 


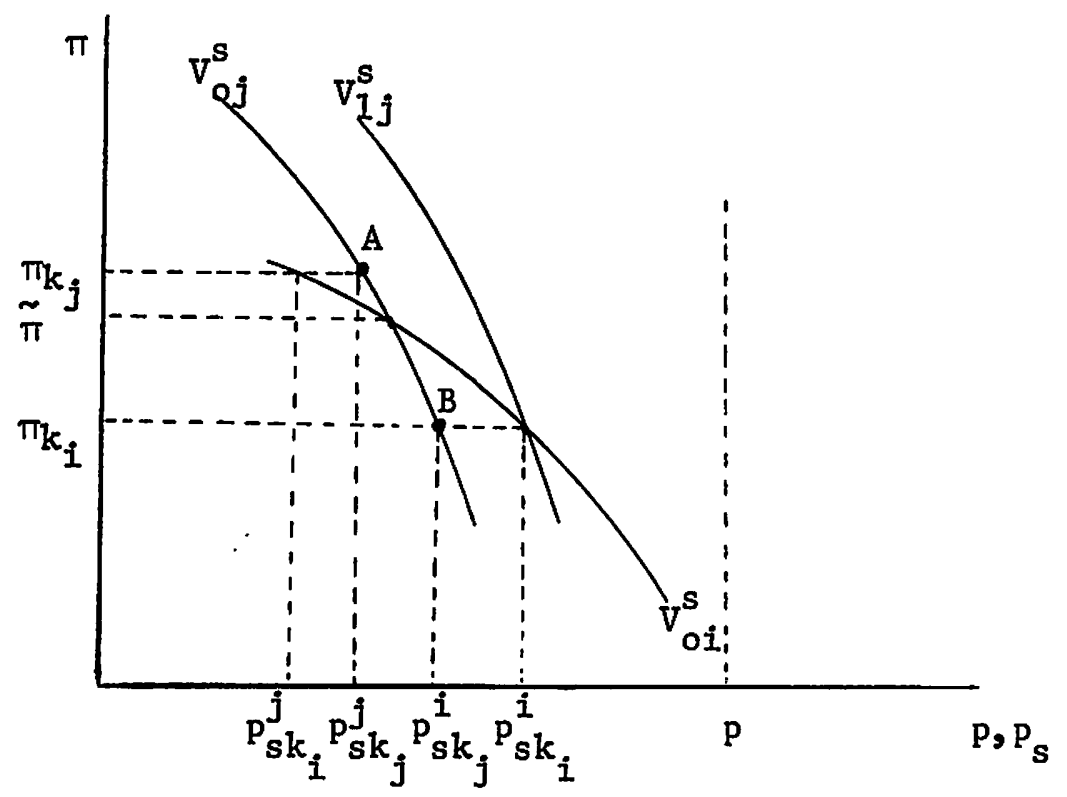

FIGURE 2 


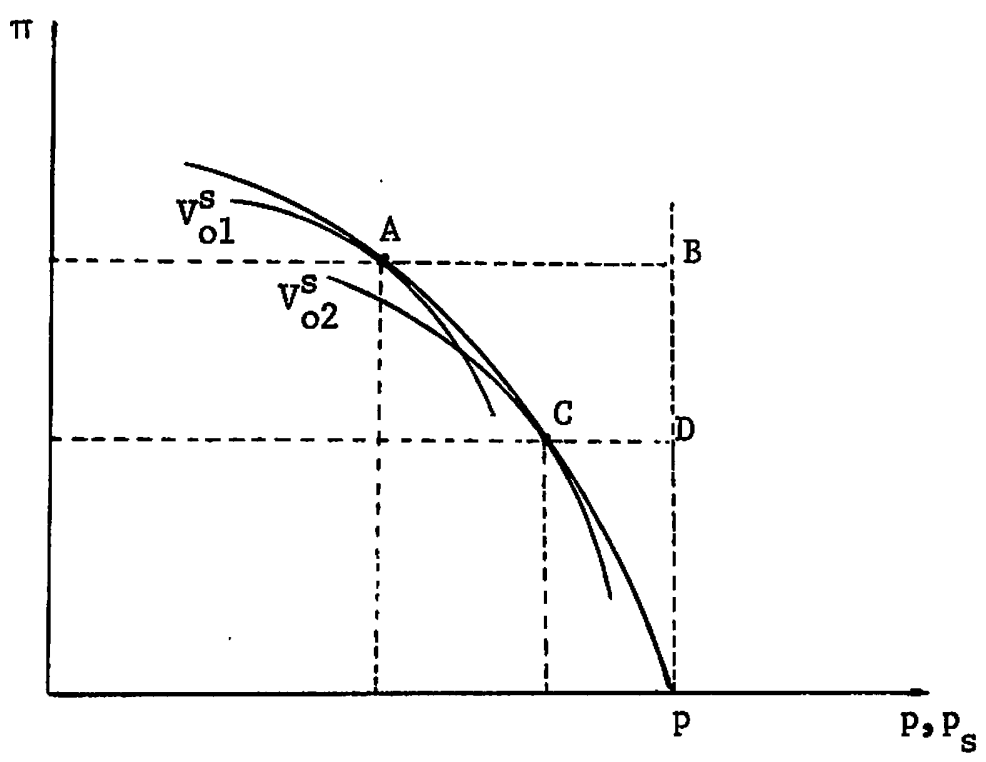

FIGURE 3 
1982

8201C Manning, Richard and James R. Markusen: DYNAMIC NON-SUBSTITUTION AND LONG RUN PRODUCTION POSSIBILITIES

8202C Feenstra, Robert and Ken Judd: TARIFFS, TECHNOLOGY TRANSFER, AND WELFARE

8203C Ronald W. Jones and Douglas D. Purvis: INTERNATIONAL DIFFERENCES IN RESPONSE TO COMMON EXTERNAL SHOCKS: THE ROLE OF PURCHASING POWER PARITY

8204C James A. Brander and Barbara J. Spencer: INDUSTRIAL STRATEGY WITH COMMITTED FIRMS

8205C Whalley, John: THE NORTH-SOUTH DEBATE AND THE TERMS OF TRADE: AN APPLIED GENERAI EQUILIBRIUM APPROACH

8206C Betancourt, Roger; Christopher Clague and Arvind Panagariya: CAPITAL UTILIZATION IN GENERAL EQUILIBRIUM

8207C Mansur, Ahsan H.: ON THE ESTIHATION OF IMPORT AND EXPORT DEMAND ELASTICITIES AND ELASTICITY PESSIMISM

8208C Whalley, J. and Randy Wigle: PRICE AND QUANTITY RIGIDITIES IN ADJUSTMENT TO TRADE POLICY CHANGES: ALTERNATIVE FORMULATIONS AND INITIAL CALCULATIONS

8209C DSU Jimenez, E.: SQUATTING AND COMMUNITY ORGANIZATION IN DEVELOPING COUNTRIES: A CONCEPTUAL FRAMEWORK

$8210 C$ Grossman, G.M.: INTERNATIONAL COMPETITION AND THE UNIONIZED SECTOR

8211C Laidler, D.: FRIEDMAN AND SCHWARTZ ON MONETARY TRENDS--A REVIEW ARTICLE

8212C Imam, H: and John khalley: INCIDENCE ANALYSIS OF A SECTOR SPECIFIC MINIMUM WAGE IN A TWO SECTOR HARRIS-TODARO MODEL

8213C Markusen, James R, and James R. Melvin: THE GAINS FROM TRADE THEOREM WITH INCREASING RETURNS TO SCALE

8214C Harris, Richard: INDUSTRIAL ORGANIZATION AND THE GENERAL EQUILIBRIUM COSTS OF PROTECTION IN SMALL OPEN ECONOMIES

8215C Laidler, David: DID MACROECONOMICS NEED THE RATIONAL EXPECTATIONS REVOLUTION?

8216C John Whalley and Randall Wigle: ARE DEVELOPED COUNTRY MULTILATERAL TARIFF REDUCTIONS NECESSARILY BENEFICIAL FOR THE U.S.? 
8217 Bade, Robin and Michael Parkin. IS STERLING M3 THE RIGHT AGGREGATE?

8218 Kosch, Bernd. FIXED PRICE EQUILIBRIA IN OPEN ECONOMIES

$\underline{1983}$

8301 Harrison, Glenn and Larry Kimbell. ON THE SOLUTION OF GENERAL EQUILIBRIUM MODELS

8302 Melvin, James. A GENERAL EQUILIBRIUM ANALYSIS OF CANADIAN OIL POLICY

8303 Markusen, James and Lars Svensson. TRADE IN GOODS AND FACTORS WITH INTERNATIONAL DIFFERENCES IN TECHNOLOGY

8304 Mohammad, Sharif and John Whalley. RENT SEEKING IN INDIA: ITS COSTS AND POLICY SIGNIFICANCE 